\title{
Ribosomal protein L34 is a potential prognostic biomarker and therapeutic target in hilar cholangiocarcinoma
}

\author{
Jianxin Qian ${ }^{1,2+}$, Lin $\mathrm{Xu}^{3 \dagger}$, Wenlong $\mathrm{Yu}^{4 \dagger}$, Xiaoqiang $\mathrm{Gu}^{2 \dagger}$, Yongjun Zuo ${ }^{5}$, Ying Chen ${ }^{6}$, Feng Xie ${ }^{4,7^{*}}$ \\ and Lixin Wei ${ }^{i^{*}}$ (D)
}

\begin{abstract}
Background: Ribosomal protein 34 (RPL34) is a highly conserved protein belonging to the 60S large subunit of mammalian ribosomes that has been found to be dysregulated in a variety of human tumors. However, there are limited results that illuminate the role and expression profiles of RPL34 in hilar cholangiocarcinoma (HCCA).

Methods: RPL34 expression was detected in human HCCA by immunohistochemistry. The relationship of RPL34 expression with clinical outcomes was evaluated by univariate and multivariate analyses. The effect of RPL34 on cell migration and tumor growth was detected after silencing endogenous RPL34 expression.

Results: RPL34 was overexpressed in HCCA compared with normal tissue samples and correlated significantly with regional lymph node metastasis and poorly/undifferentiated tumors. Patients with high RPL34 expression had a shorter time to recur and a poorer outcome than those without RPL34 expression. Silencing RPL34 inhibited cell proliferation and migration in vitro and upregulated E-cadherin. Silencing RPL34 also attenuated tumor growth in vivo.

Conclusions: Our findings suggested that RPL34 might serve as a promising prognostic biomarker and a potential therapeutic target for the treatment of HCCA.
\end{abstract}

Keywords: Ribosomal protein L34 (RPL34), Hilar cholangiocarcinoma, Tumor recurrence, Prognosis

\section{Background}

Hilar cholangiocarcinoma (HCCA), which is characterized by invasive tumor biology, low surgical resectability, high recurrence and poor survival outcome, is one of the most intractable cancers. HCCA accounts for $60 \%$ of all cholangiocarcinomas [1]. The ideal treatment for HCCA is surgical resection. However, the recurrence rate after primary surgery often reaches $50-75 \%$, which exclusively

\footnotetext{
*Correspondence: 2785133503@qq.com; weilixin_smmu@163.com ${ }^{\dagger}$ Jianxin Qian, Lin Xu and Wenlong Yu contributed equally to this work

${ }^{1}$ Tumor Immunology and Gene Therapy Center, Third Affiliated Hospital of Second Military Medical University, Shanghai 200438, China

${ }^{4}$ Departments of Surgery, Third Affiliated Hospital of Second Military Medical University, Shanghai 200438, China

Full list of author information is available at the end of the article
}

depends on the feasibility of surgical resection with a negative margin. The 5-year survival rate of patients undergoing surgery is still only $30-42 \%[2,3]$. According to the low surgical resectability and poor survival outcomes, novel prognostic factors and treatment strategies are desired to play a role in clinical practice. As a consequence, gaining insight into the molecular mechanisms is essential to predict patient prognosis and improve clinical strategies.

Mammalian ribosomes include a $40 \mathrm{~S}$ subunit and a 60S subunit, which consist of 4 ribosomal RNAs and approximately 80 ribosomal proteins. On the basis of the size of the subunits they derive from, those ribosomal proteins can be divided into two classes: RPS (ribosomal proteins in small subunits) and RPL (ribosomal

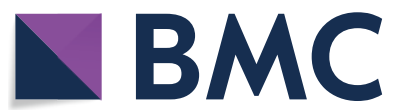

(c) The Author(s) 2020. This article is licensed under a Creative Commons Attribution 4.0 International License, which permits use, sharing, adaptation, distribution and reproduction in any medium or format, as long as you give appropriate credit to the original author(s) and the source, provide a link to the Creative Commons licence, and indicate if changes were made. The images or other third party material in this article are included in the article's Creative Commons licence, unless indicated otherwise in a credit line to the material. If material is not included in the article's Creative Commons licence and your intended use is not permitted by statutory regulation or exceeds the permitted use, you will need to obtain permission directly from the copyright holder. To view a copy of this licence, visit http://creativecommons.org/licenses/by/4.0/. The Creative Commons Public Domain Dedication waiver (http//creativecommons.org/publicdomain/zero/1.0/) applies to the data made available in this article, unless otherwise stated in a credit line to the data. 
proteins in large subunits). In a previous study, the function of ribosomal proteins was mainly related to the structural stability of rRNAs in mature subunits and the accurate folding of rRNAs in ribosomal assembly [4-6]. However, in addition to its function in ribosomal assembly, ribosomal proteins also participate in other physiological functions depending on their expression level, such as gene expression, nucleic acid replication, DNA repair, and the cell cycle [7]. Under pathological conditions, the expression of ribosomal proteins has a significant role in disease progression. Aberrant regulation of ribosomal proteins influences tumorigenesis, leukemogenesis and Turner syndrome [8,9]. A number of ribosomal proteins have diverse roles in cancer cell proliferation and tumor growth. In gastric cancer, for example, RPL6, RPL13, RPL15 and RPS13 have high expression and increase cancer cell proliferation and promote cancer development [10-13]. RPL19 is highly expressed in prostate cancer and colorectal cancer, which correlates significantly with poor patient outcomes $[14,15]$. The secretion of PRS3 could result in drug resistance and malignancy in various cancer cells [16]. RPL34 is a highly conserved protein belonging to the 60S large subunit, which has a zinc finger motif [17]. In several cancers, RPL34 was dysregulated in various cancers, and silencing RPL34 led to inhibition of cell proliferation and migration [18-23]. However, there are not enough results to illuminate the role of RPL34 and its clinical significance in hilar cholangiocarcinoma.

In this study, we detected the expression level of RPL34 protein in 121 HCCA tissues and adjacent tissues and analyzed the relationship between its expression level and patient outcome.

\section{Results}

\section{Expression profiles of RPL34 protein in tumor tissues and adjacent tissues}

Positive staining of RPL34 protein was mainly localized in the cytoplasm of tumor cells, while adjacent noncancerous tissues showed negative or extremely weak expression of RPL34 (Fig. 1a). According to the category standard, $77.7 \%(94 / 121)$ of HCCAs had high RPL34 expression (Fig. 1b, c), and the other 22.3\% (27/121) of HCCAs had negative RPL34 expression (Fig. 1d). In RPL34-positive tumors, nearly all tumor cells showed positive staining of RPL34. However, the level of RPL34-high expression staining seemed to be different even in the same tumor slide (Fig. 2a). As shown in Fig. 2, the level of RPL34-positive staining was relatively lower in well-differentiated tumor regions (Fig. 2b) than in invasive tumor cells (Fig. 2c, d).

\section{The association between RPL34-positive expression} and clinicopathological parameters

Table 1 lists the association between RPL34-positive expression and clinicopathological parameters of HCCA. The results indicated that RPL34 expression was statistically related to tumor $\mathrm{N}$ stage and differentiation degree. RPL34 expression was more often observed in poorly differentiated tumors than in highly/moderately differentiated tumors $(82.0 \%$ vs $30.0 \%, P=0.001)$. Moreover, patients with LN metastasis were more likely to have a high expression level of RPL34 than those without LN metastasis $(84.6 \%$ vs $69.6 \%, P=0.049)$. There was no significant correlation between RPL34 expression and age, sex, tumor size or disease stage $(P>0.05)$.

\section{RPL34 expression and prognosis of patients with HCCA}

The predictive and prognostic values of RPL34 were investigated in these patients with CCA. The follow-up was not available for three patients. The clinicopathological parameters, such as age, sex, tumor size, regional lymph node metastasis, positive margin, differentiation, T stage, and TNM stage, were used for the following univariate analysis of tumor recurrence and overall survival. In accordance with previous reports, positive margin (1.75 years for negative margin vs 0.75 years for positive margin, $P=0.024)$, regional lymph nodes ( 1.83 years for without LN metastasis vs 0.92 for LN metastasis, $P=0.015)$, and advanced disease stage (2.73 years for stage I/II vs 1.0 year for stage III/IV, $P=0.023$ ) were associated with tumor recurrence in HCCA. In addition, patients with RPL34-positive tumors had a shorter time to recur than those with RPL34-negative expression (1.46 years vs 3.73 years, $\mathrm{P}<0.001$ ) (Fig. 3 , Table 2 ). In the Cox model, RPL34 expression was the only independent predictive factor for tumor recurrence.

For overall survival, positive margin (2.46 years for negative margin vs 1.64 years for positive margin, $P=0.013)$, T stage (2.51 years for T1/T2 vs 1.75 for T3/ T4, $P=0.019$ ), regional lymph nodes (2.72 years for without LN metastasis $v s 1.68$ for LN metastasis, $P=0.001$ ), advanced disease stage (2.96 years for stage I/II vs 1.82 years for stage III/IV, $P=0.003)$, and poor differentiation (3.10 years for well/moderately differentiated tumors vs 2.02 years for poorly differentiated/undifferentiated tumors, $P=0.025$ ) correlated significantly with worse patient outcomes. In particular, patients with RPL34-positive tumors had a decreased overall survival compared with those without RPL34 expression (1.70 years vs 3.63 years, $\mathrm{P}<0.001$ ) (Fig. 4 , Table 3 ). In the multivariate Cox model, RPL34 expression was also the only independent prognostic factor for patients with HCCA (Table 3). 

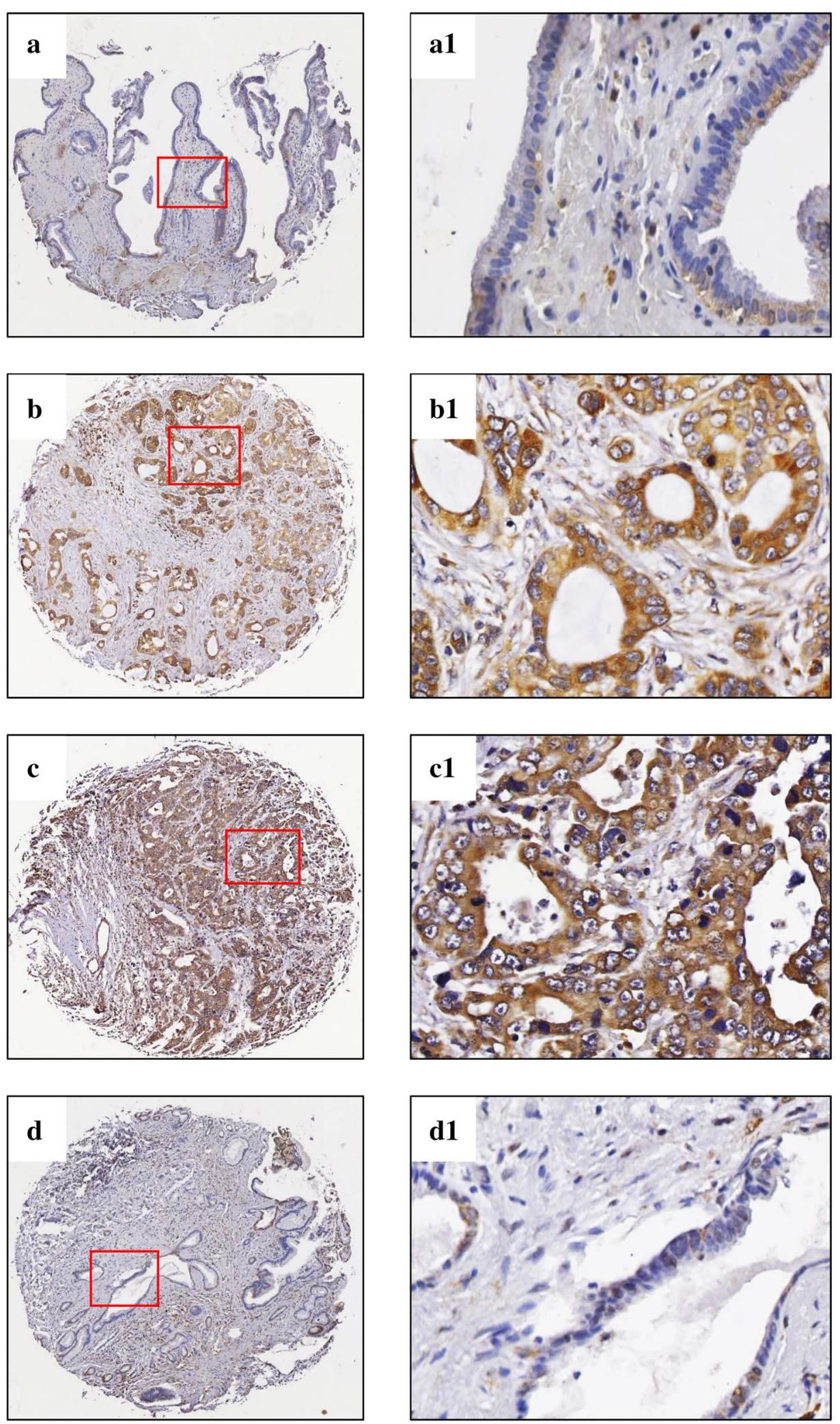

Fig. 1 RPL34 expression in tumor tissues and noncancerous tissues. a Negative expression of RPL34 in noncancerous bile duct tissues; $\mathbf{b}$, c

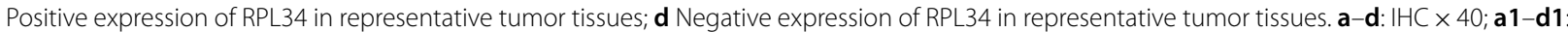
$\mathrm{IHC} \times 200$ 

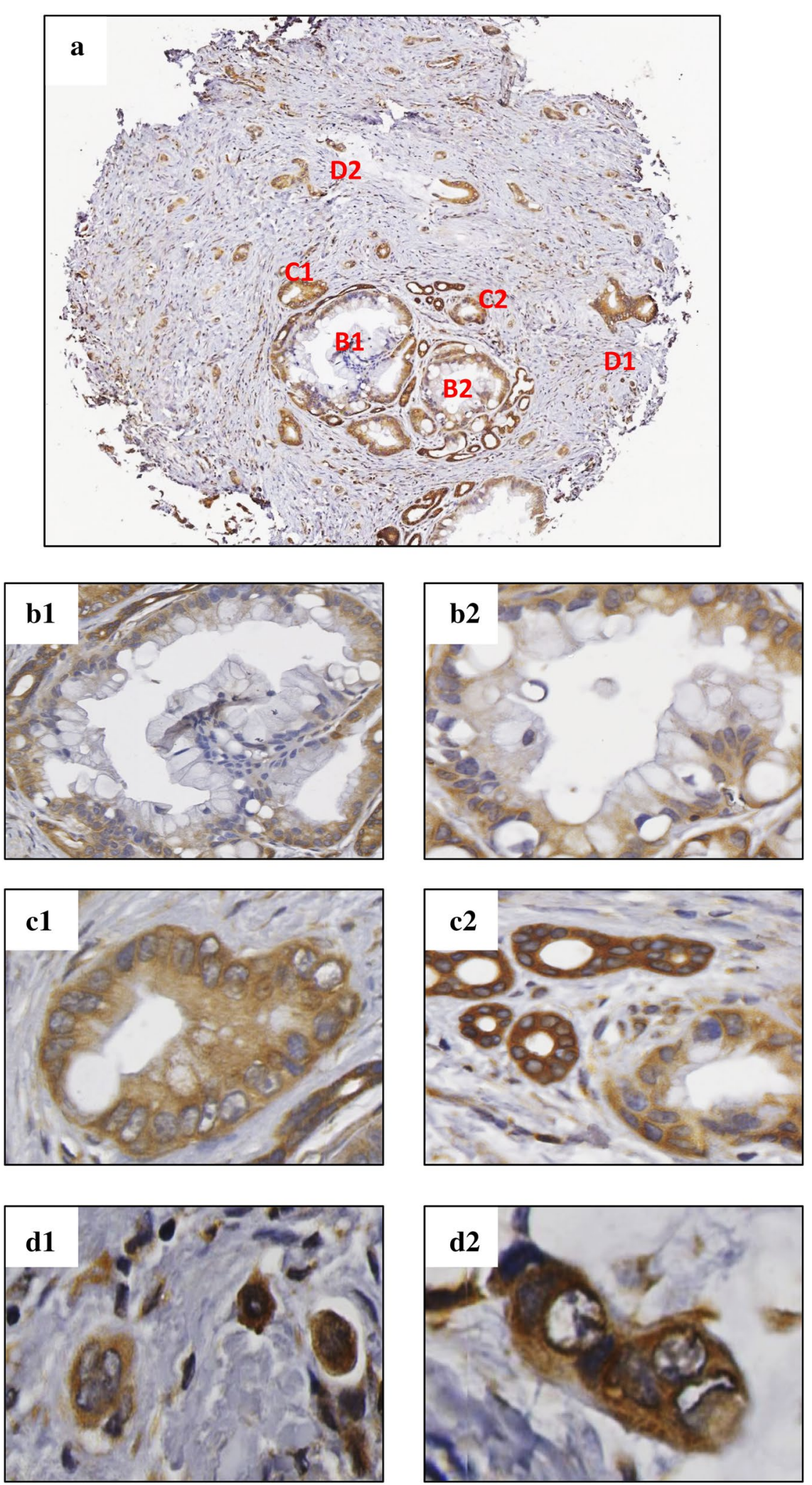

Fig. 2 Heterogeneity of RPL34 expression in the same tumor. a RPL34 expression in a representative tumor sample; b1, b2 weak expression of RPL34 in a well-differentiated region; c1-d2 High expression of RPL34 in invasive tumor cells. a IHC $\times$ 40; b1-d $11 H C \times 200$ 
Table 1 Association between RPL34 positive expression and clinic-pathological parameters

\begin{tabular}{|c|c|c|c|}
\hline Parameters & No. & $\begin{array}{l}\text { RPL34 } \\
\text { n (\%) }\end{array}$ & $P$ value \\
\hline \multicolumn{4}{|l|}{ Age } \\
\hline$\leq 55$ years & 55 & $42(76.4)$ & 0.75 \\
\hline$>55$ years & 66 & $52(78.8)$ & \\
\hline \multicolumn{4}{|l|}{ Gender } \\
\hline Male & 82 & $64(78.0)$ & 0.889 \\
\hline Femal & 39 & $30(76.9)$ & \\
\hline \multicolumn{4}{|l|}{ Tumor size } \\
\hline$\leq 6 \mathrm{~cm}$ & 57 & $42(73.7)$ & 0.318 \\
\hline$>6 \mathrm{~cm}$ & 64 & $52(81.2)$ & \\
\hline \multicolumn{4}{|l|}{ T stage } \\
\hline$|/| \mid$ & 73 & $58(79.5)$ & 0.565 \\
\hline III/IV & 48 & $36(75.0)$ & \\
\hline \multicolumn{4}{|l|}{ N stage } \\
\hline No & 56 & $39(69.6)$ & 0.049 \\
\hline Yes & 65 & $55(84.6)$ & \\
\hline \multicolumn{4}{|l|}{ Differentiation } \\
\hline High/moderate & 10 & $3(30.0)$ & 0.001 \\
\hline Poor & 111 & $91(82.0)$ & \\
\hline \multicolumn{4}{|l|}{ Disease stage } \\
\hline$|/| \mid$ & 38 & $28(73.7)$ & 0.474 \\
\hline III/IV & 83 & $66(79.5)$ & \\
\hline
\end{tabular}

\section{Knockdown of RPL34 inhibited HCCA cell growth and migration in vitro and tumor growth in vivo}

To examine the biological role of RPL34 in HCCA, we employed shRNA against RPL34 to stably knock down RPL34 in QBC939 cells and detected the effect of RPL34 on cell proliferation by the CCK- 8 assay and cell migration using Transwell migration assays (Fig. 5). Silencing of RPL34 expression suppressed the proliferation of QBC939 cells (Fig. 5a). In the xenograft tumor models, tumors formed by RPL34-silenced QBC939 cells were smaller in volume than the tumors formed by control cells (Fig. 5b). Moreover, silencing RPL34 sharply inhibited the migration of QBC939 cells (Fig. 5c). We further investigated the potential mechanism by which sh-RPL34 inhibited QBC939 cell proliferation and migration. Knockdown of RPL34 significantly increased the protein expression levels of E-cadherin compared with the sh-NC group (Fig. 5d) but did not affect the expression of metabolism-related proteins (Fig. 5e).

\section{Discussion}

In the present study, we systemically investigated the expression profiles of RPL34 in human HCCA samples and aimed to confirm its biological role in cancer progression. RPL34 was extremely highly expressed in HCCA cells and correlated significantly with regional lymph node metastasis. Knockdown of RPL34 efficiently inhibited cell proliferation and migration in vitro and attenuated tumor growth in vivo in HCCA cell lines. Finally, RPL34 expression was an adverse predictor of tumor recurrence and poor prognosis in patients with HCCA.

Previous studies have mainly focused on mosquitoes and plants [24] but are rare in cancer development. In the past 3 years, however, increasing studies have demonstrated that RPL34 is deregulated in various types of human cancers, including nonsmall lung cancer, gastric cancer, esophageal cancer and prostate cancer [18-20, 22]. RPL34 could regulate cell cycle transition by inhibiting Cdk4 and Cdk5 in HeLa cells [25]. In nonsmall lung cancer and gastric cancer, overexpression of RPL34 contributes to cancer cell proliferation [18, 20]. For osteosarcoma patients, high expression of RPL34 often indicates a poor prognosis [26]. Silencing RPL34 via small interfering RNA (siRNA) can inhibit Saso-2 cell growth, increase cell apoptosis and arrest cells in G2/M phase. In the present study, we observed higher RPL34 expression in tumor tissues than in noncancerous tissues, which was the same as the expression in other cancers $[18,20$, 26]. Regional lymph node metastasis is an important adverse factor in predicting tumor recurrence and poor survival of patients with solid tumors. Our data showed that RPL34-positive tumors had a higher chance of being accompanied by regional lymph node metastasis. Most interestingly, even in the same tumor, invasive tumor cells had a higher level of RPL34 expression than less invasive tumor cells. Generally, well/moderately differentiated tumor cells had less invasive ability than poorly/ undifferentiated tumor cells. Our data also demonstrated higher expression of RPL34 in well/moderately differentiated tumor regions than in poorly/undifferentiated tumor regions. Moreover, an in vivo study revealed that knockdown of RPL34 led to inhibition of cell proliferation, especially cell migration. All these data confirmed the significant role of RPL34 in cancer development and progression.

HCCA is a highly aggressive tumor with poor 5 -year survival. A number of clinicopathological variables, such as lymph node metastasis, TNM stage, and negative surgical margins, have been proposed to be responsible for tumor recurrence and overall survival. In the present study, we proved that lymph node metastasis, surgical margins, and disease stage were unfavorable factors for predicting tumor recurrence. In agreement with previous studies, none of these parameters could be regarded as independent predictors of tumor recurrence or patient outcome in a small cohort. Therefore, it is necessary to 


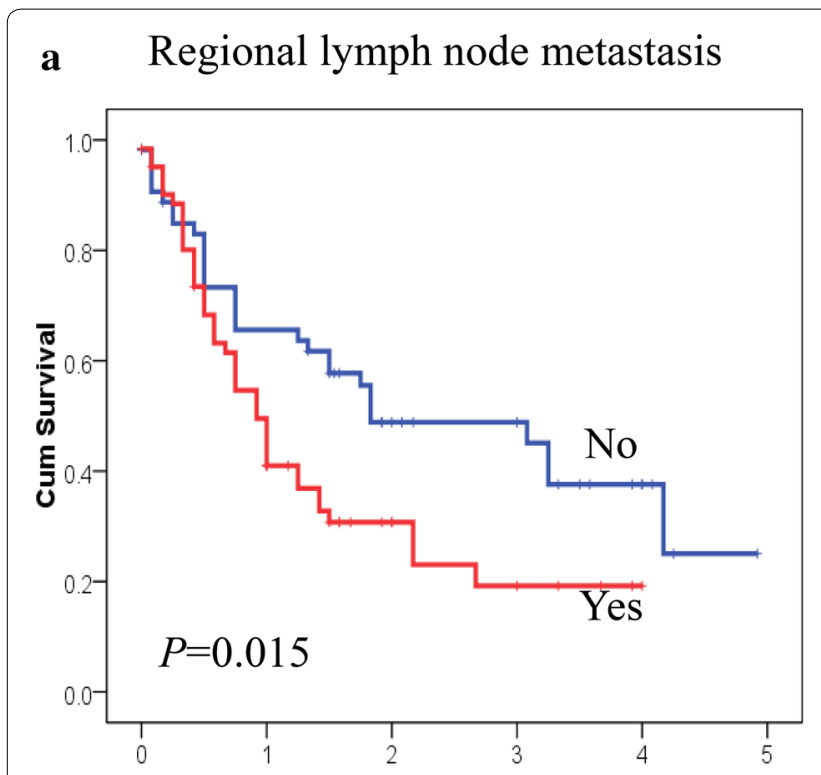

DFS

C

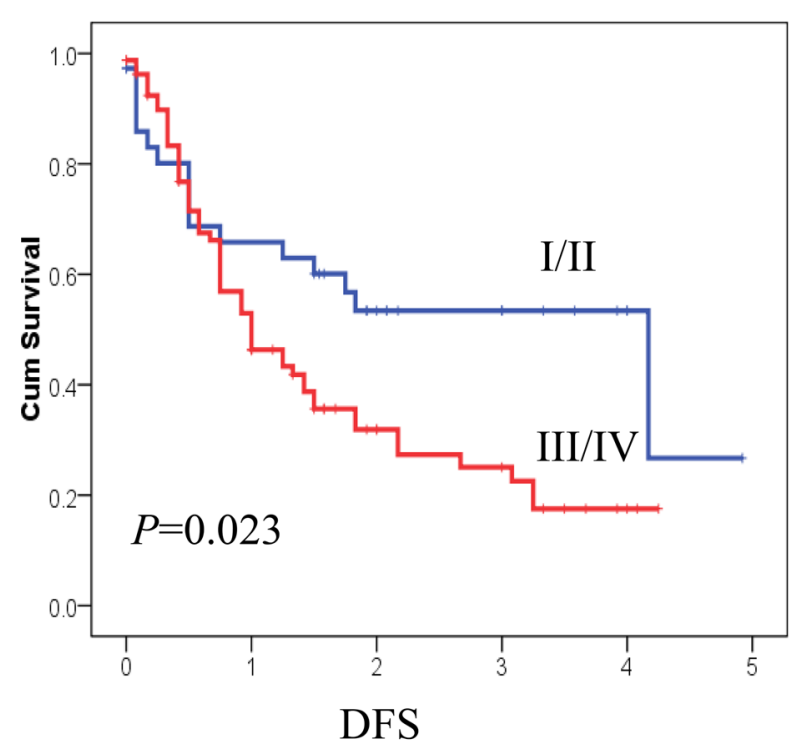

b Positive margin

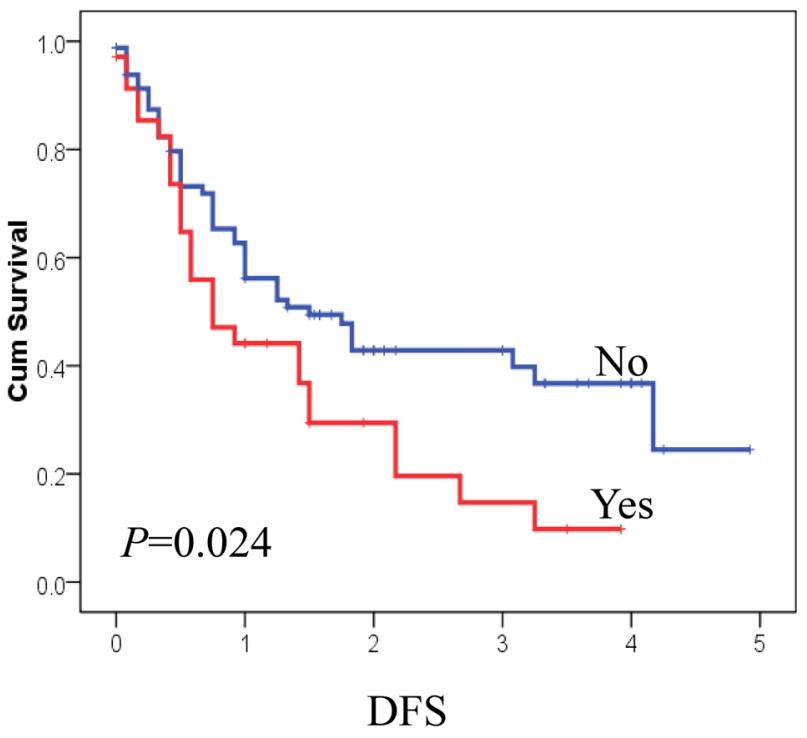

d $\quad$ RPL34

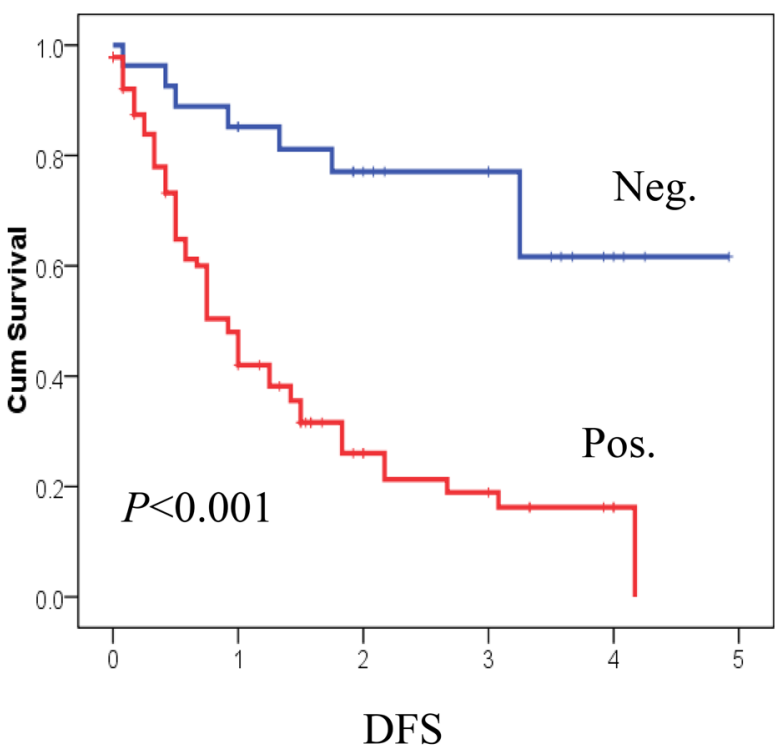

Fig. 3 Kaplan-Meier curves of disease-free survival (DFS) in patients with hilar cholangiocarcinoma. a DFS was significantly worse in patients with regional lymph node metastasis than in those without lymph node metastasis ( 0.92 years vs 1.83 years, $P=0.015)$; $b$ DFS was significantly worse in patients with positive surgical margins than in those with negative surgical margins $(0.75$ years vs 1.50 years, $P=0.024)$; $c$ DFS was significantly worse in patients with advanced disease stage than in those with early disease stage ( 1.00 year vs 2.73 years, $P=0.023)$; $\mathbf{d}$ DFS was significantly worse in patients with RPL34-positive tumors than in those with RPL34-negative tumors ( 1.46 years vs 3.73 years, $P<0.001$ )

introduce biological markers (VEGF, CA199, HER-2, etc.) into the Cox regression model aiming to monitor HCCA progression and evaluate the outcome of patients with HCCA. Previous studies have shown that the expression of biological markers such as PRR11, PKM2, FoxM1, and
ADAM17 is predictive of tumor recurrence and overall survival in HCCA [27-29]. In the present study, we provided strong evidence that patients with RPL34-expressing tumors were more likely to recur and had a poorer outcome than those without RPL34-expressing tumors. 


\begin{tabular}{|c|c|c|c|c|c|c|}
\hline Variable & No. & $\begin{array}{l}\text { Mean survival } \\
\text { (years) }\end{array}$ & $\begin{array}{l}\text { P value } \\
\text { (univariate) }\end{array}$ & $\begin{array}{l}\text { P value } \\
\text { (multivariate) }\end{array}$ & Hazard ratio & $95 \% \mathrm{Cl}$ \\
\hline \multicolumn{7}{|c|}{ Positive margin } \\
\hline No & 83 & 1.50 & 0.024 & & & \\
\hline Yes & 35 & 0.75 & & & & \\
\hline \multicolumn{7}{|c|}{ Regional lymph nodes positive } \\
\hline No & 55 & 1.83 & 0.015 & & & \\
\hline Yes & 63 & 0.92 & & & & \\
\hline \multicolumn{7}{|l|}{ TNM stage } \\
\hline$|/| \mid$ & 37 & 2.73 & 0.023 & & & \\
\hline III/IV & 81 & 1.00 & & & & \\
\hline \multicolumn{7}{|l|}{ RPL34 } \\
\hline Negative & 27 & 3.73 & $<0.001$ & $<0.001$ & 0.207 & $0.096-0.445$ \\
\hline Positive & 91 & 1.46 & & & & \\
\hline
\end{tabular}

This finding suggested that RPL34 overexpression is an important event in HCCA tumorigenesis and is a useful biomarker for predicting tumor recurrence and outcome.

Mechanistically, silencing RPL34 suppressed cell proliferation by increasing apoptosis and cell cycle arrest in gastric cancer (RNAi-mediated RPL34 knockdown suppresses the growth of human gastric cancer cells). In esophageal cancer, knockdown of RPL34 could upregulate E-cadherin expression and downregulate N-cadherin expression, indicating that depletion of RPL34 inhibited cell migration and invasion by suppressing the EMT phenotype [22]. Here, we demonstrated that silencing RPL34 increased E-cadherin expression but did not downregulate $\mathrm{N}$-cadherin, indicating another potential mechanism involved in RPL34 regulation. Given the importance of cancer metabolism in tumorigenesis and metastasis, we detected the expression levels of several metabolismrelated biomarkers, namely, PKM2, PCK2, and AKR1C1, in HCCA cells after silencing RPL34. However, silencing RPL34 failed to decrease the expression of the above biomarkers. These results suggest that RPL34 has a more complex underlying mechanism for promoting tumor development and metastasis. Therefore, the limitations of this study are the lack of direct molecular mechanisms of RPL34 in tumor progression, which will be further investigated in future studies.

\section{Conclusion}

Combined with the predictive role of RPL34 in tumor recurrence and overall survival, our findings suggested that RPL34 might serve as a promising prognostic biomarker and a potential therapeutic target for the treatment of HCCA.

\section{Methods}

\section{Tissue samples and ethics statement}

Patients with HCCA who underwent tumor resection at the Eastern Hepatobiliary Hospital between January 2004 and December 2008 were reviewed by two pathologists. Only adenocarcinoma, not other tumor types, such as neuroendocrine carcinomas, was enrolled in this study. Finally, a total of 121 patients with HCCA and 25 with matched adjacent noncancerous bile duct epitheliums were used for the following study. The median age of these patients was 55 years, ranging from 30.5 to 79 years. The detailed information of these patients is listed in Table I. Of the enrolled patients, 82 $(67.8 \%)$ were male, 39 (32.2\%) were female, 48 (39.7\%) were diagnosed with stage III/IV disease, and 73 (60.3\%) exhibited stage I/II disease according to AJCC TNM staging for all types of cholangiocarcinoma [30]. A total of 118 of 121 (97.5\%) of the enrolled patients were available for follow-up through telephone or mail. PFS (progression-free survival) refers to the period of time between the surgical resection of the tumor and the recurrence of HCCA. OS (overall survival) refers to the period between the time of cholangiocarcinectomy and patient death. None of these patients received any preoperative treatment, either radiotherapy or chemotherapy. All patients received standard courses of postoperative adjuvant treatment according to the NCCN guidelines. Informed consent for the study purpose of the resected specimens was signed by all patients. The use of the resected specimens and clinical information was approved by the Eastern Hepatobiliary Hospital Institutional Review Boards. 


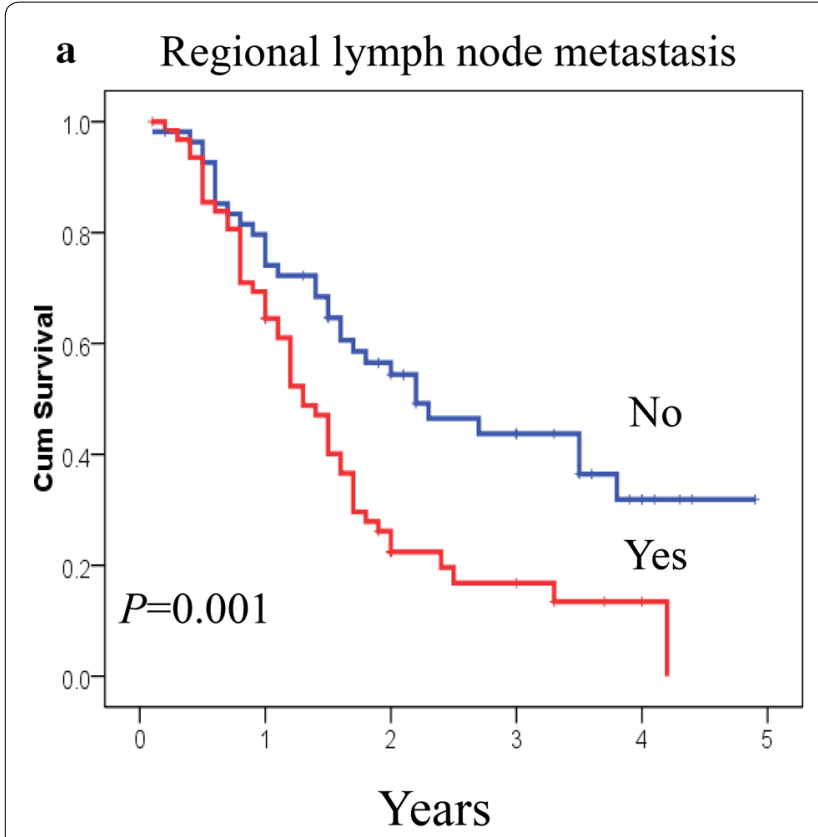

b Positive margin

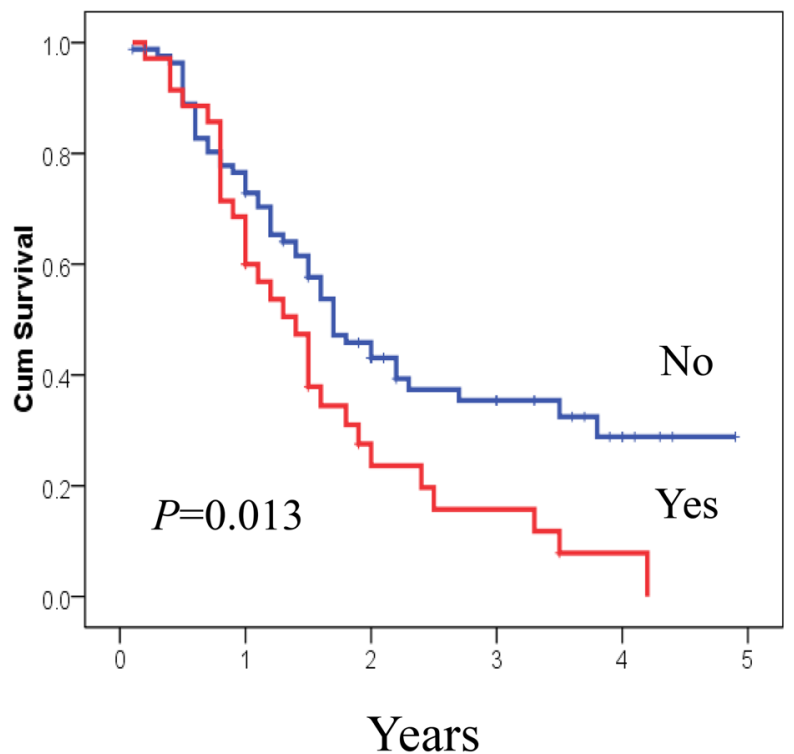

d

RPL34

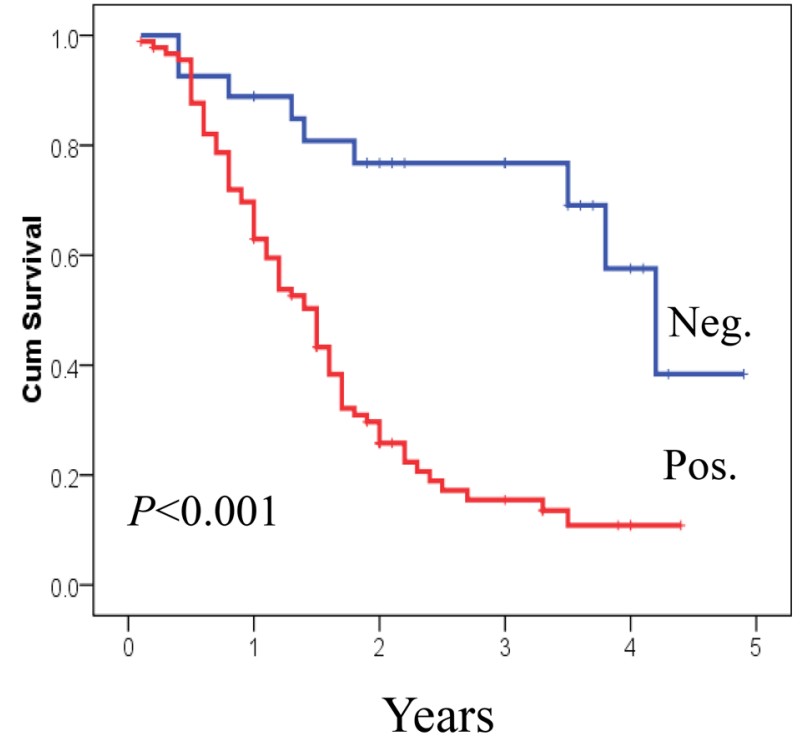

Fig. 4 Kaplan-Meier curves of overall survival (OS) in patients with hilar cholangiocarcinoma. a OS was significantly worse in patients with regional lymph node metastasis than in those without lymph node metastasis ( 1.68 years vs 2.72 years, $P=0.001)$; $\mathbf{b}$ OS was significantly worse in patients with positive surgical margins than in those with negative surgical margins ( 1.64 years vs 2.46 years, $P=0.013)$; $c$ OS was significantly worse in patients with advanced disease stage than in those with early disease stage (1.82 years vs 2.96 years, $P=0.003)$; $\mathbf{d}$ OS was significantly worse in patients with RPL34-positive tumors than in those with RPL34-negative tumors ( 1.70 years vs 3.63 years, $P<0.001$ )

\section{Immunohistochemical staining and analysis}

Four-micron paraffin-embedded sections of tumor specimens were prepared and were microwave-treated in $0.01 \mathrm{~mol} / \mathrm{l}$ citrate buffer $(\mathrm{pH} 6.0)$ at $99{ }^{\circ} \mathrm{C}$ for $4 \mathrm{~min}$. After inhibiting endogenous peroxide activity by $\mathrm{H}_{2} \mathrm{O}_{2}$ and blocking in goat serum for $10 \mathrm{~min}$, anti-RPL34 antibody (rabbit, 1:50, Abcam, ab129394) was incubated with the sections at $4{ }^{\circ} \mathrm{C}$ for $24 \mathrm{~h}$. TMAs were then washed 3 times with PBS buffer for $10 \mathrm{~min}$. An S-p (Streptavidin-Biotin) kit (\#KIT-9720, MAIXIM, Fuzhou, China) 
Table 3 Univariate and Multivariate Analysis of Variables Associated with Overall Survival in Patients with hilar cholangiocarcinoma

\begin{tabular}{|c|c|c|c|c|c|c|}
\hline Variable & No. & $\begin{array}{l}\text { Mean survival } \\
\text { (years) }\end{array}$ & $\begin{array}{l}\text { P value } \\
\text { (univariate) }\end{array}$ & $\begin{array}{l}\text { P value } \\
\text { (multivariate) }\end{array}$ & Hazard ratio & $95 \% \mathrm{Cl}$ \\
\hline \multicolumn{7}{|l|}{ Positive margin } \\
\hline No & 83 & 2.46 & 0.013 & & & \\
\hline Yes & 35 & 1.64 & & & & \\
\hline \multicolumn{7}{|l|}{ T stage } \\
\hline $\mathrm{T} 1 / \mathrm{T} 2$ & 70 & 2.51 & 0.019 & & & \\
\hline $\mathrm{T} 3 / \mathrm{T} 4$ & 48 & 1.75 & & & & \\
\hline \multicolumn{7}{|c|}{ Regional lymph nodes positive } \\
\hline No & 55 & 2.72 & 0.001 & & & \\
\hline Yes & 63 & 1.68 & & & & \\
\hline \multicolumn{7}{|l|}{ TNM stage } \\
\hline$|/| \mid$ & 37 & 2.96 & 0.003 & & & \\
\hline III/IV & 81 & 1.82 & & & & \\
\hline \multicolumn{7}{|l|}{ RPL34 } \\
\hline Negative & 27 & 3.63 & $<0.001$ & 0.001 & 0.254 & $0.120-0.538$ \\
\hline Positive & 91 & 1.70 & & & & \\
\hline \multicolumn{7}{|l|}{ Differentiation } \\
\hline Well/moderate & 10 & 3.10 & 0.025 & & & \\
\hline Poor/undifferentiated & 108 & 2.02 & & & & \\
\hline
\end{tabular}

\footnotetext{
(See figure on next page.)
}

Fig. 5 The inhibitory role of silencing RPL34 on hilar cholangiocarcinoma cells. a QBC939 cells were infected with RPL34-shRNA or NC lentivirus, and cell growth was assayed by the CCK-8 assay (shNT vs shRPL34). b QBC939 cells transfected with sh-RPL34 and the corresponding control cells $\left(5^{*} 10^{6}\right)$ were suspended in $200 \mu$ l of PBS and then injected subcutaneously into the right flank of mice. Mice were sacrificed after 21 days, the tumors were dissected, and tumor volumes were measured. c Transwell migration assays were used to evaluate the effect of RPL34 on cell migration in QBC939 cells transfected with sh-RPL34. d The protein levels of E-cadherin, N-cadherin, and PCDH9 were measured by western blot in RPL34-silenced QBC939 cells. e The protein levels of PKM2, PCK2, and AKR1C1 were measured by western blot in RPL34-silenced QBC939 cells. ${ }^{* *} p<0.01,{ }^{* * *} p<0.001$, versus the shNC group. Magnification, $\times 100$

was used to visualize the primary antibody binding to the tissues. DAB was used as the substrate for horseradish peroxidase, and the tissues were counterstained with hematoxylin. A semiquantitative scoring system was used to evaluate the expression of RPL34 under an Olympus CX31 microscope (Olympus, Center Valley, PA, USA), as previously described [27]. The staining intensity was divided into negative, 0 ; weak, 1 ; moderate, 2 ; and intense, 3 . The percentage of positively stained cells was scored as $0-1(0-100 \%)$. Theoretically, a weighted score ranging between 0 ( $0 \%$ of cells stained) and $3(100 \%$ of the cells stained at $3+$ intensity) was generated for each case [31]. A score $\geq 75$ was defined as high expression [29].

\section{Cell culture and transfection}

The human hilar cholangiocarcinoma cell line QBC939 was preserved in our lab, cultured in Dulbecco's modified Eagle's medium (DMEM) with 10\% fetal bovine serum (Invitrogen) and 1\% penicillin-streptomycin solution, and incubated at $37{ }^{\circ} \mathrm{C}$ in $5 \% \mathrm{CO}_{2}$. Lentivirus particles targeting RPL34 (sh-RPL34, TGCTGTAAGACC TAAAGTT) and its negative control (sh-NC, TTCTCC GAACGTGTCACGT) were designed and synthesized by GeneChem Co., Ltd. (Shanghai, P.R. China). For lentivirus infection, QBC939 cells were cultured in 6-well plates, and then the RPL34-shRNA-lentivirus or negative control (NC) lentivirus was added according to a multiplicity of infection (MOI). Seventy-two hours after infection, the cells were observed under a fluorescence microscope (MicroPublisher 3.3RTV; Olympus, Tokyo, Japan). At $120 \mathrm{~h}$ after infection, the cells were harvested to determine the knockdown efficiency by western blotting.

\section{Cell proliferation assay}

Stably infected QBC939 cells (RPL34-shRNA and NC) were seeded in 96-well plates and incubated in medium 


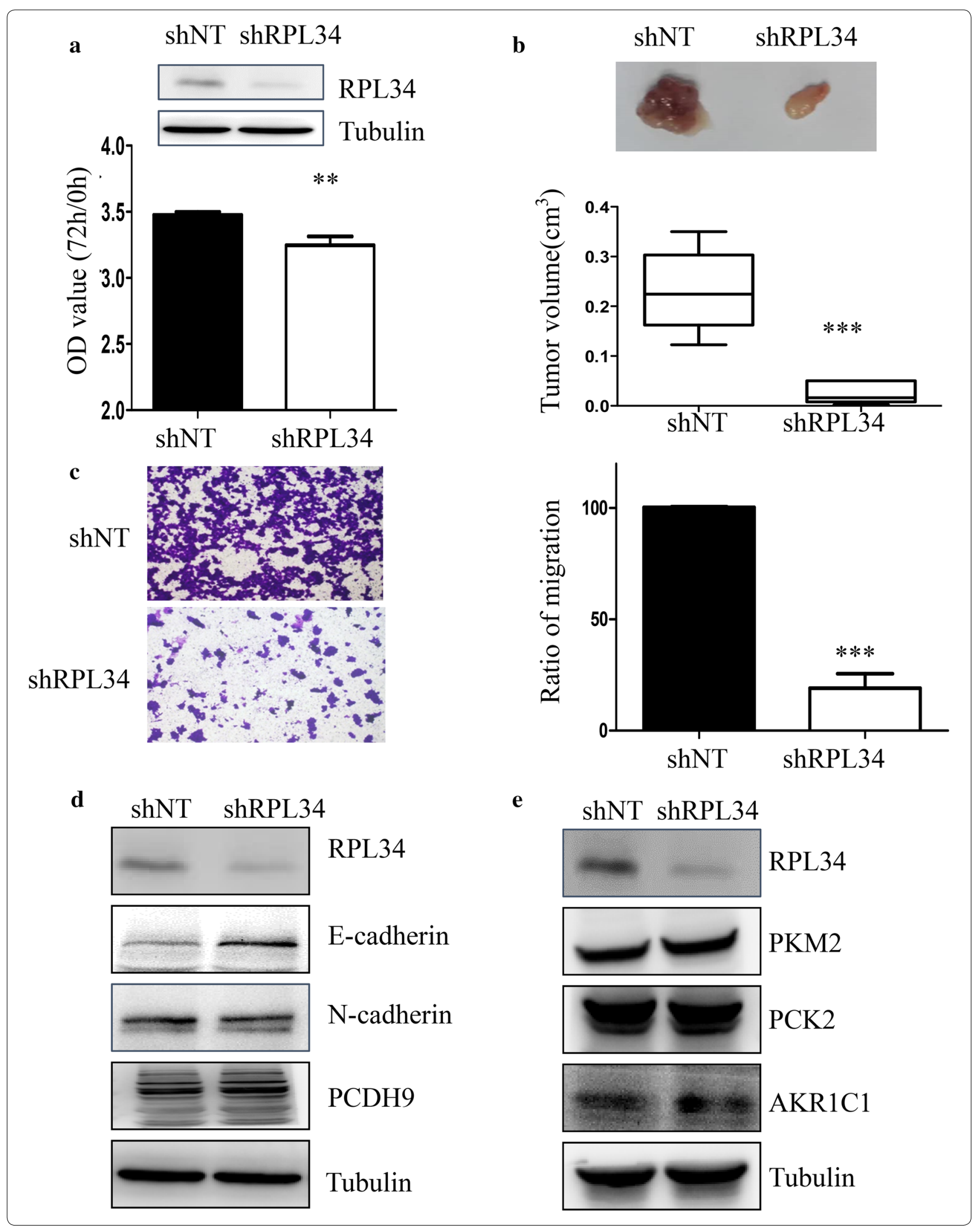


with $5 \%$ FBS. At 0 h, $24 \mathrm{~h}, 48 \mathrm{~h}$, and $72 \mathrm{~h}$, cell viability was measured by the Cell Counting Kit-8.

\section{Cell migration assays}

Stably infected QBC939 cells (RPL34-shRNA and NC) were plated in the upper chamber without Matrigel at a density of $1 \times 10^{5}$ cells per well. Then, $600 \mu \mathrm{l}$ of DMEM supplemented with $10 \%$ FBS was added to the lower chamber. Sixteen hours after incubation, the cells on the lower surface of the membrane were fixed with 95\% ethanol, stained with $0.1 \%$ crystal violet, and then counted under a light microscope (Olympus Corp., Tokyo, Japan).

\section{Western blotting}

Stably infected QBC939 cells (RPL34-shRNA and NC) were digested and disrupted by SDS cell lysis buffer. The concentration of total proteins was measured by the bicinchoninic acid (BCA) protein assay kit (TaKaRa, Japan). All proteins were separated through electrophoresis using SDS-PAGE and transferred to polyvinylidene difluoride (PVDF) membranes. The membranes were then blocked in blocking buffer (TBST buffer with 5\% low-fat milk) for $1 \mathrm{~h}$ at room temperature and incubated with anti-RPL34 antibody (1:1000), anti-E-cadherin (1:1000), anti-N-cadherin (1:1000), anti-PCDH9 (1:1000), anti-PKM2 (1:1000), anti-PCK2 (1:1000) and antiAKR1C1 (1:1000) at $4{ }^{\circ} \mathrm{C}$ overnight. After washing three times with PBS, a secondary antibody was incubated for $1 \mathrm{~h}$ at room temperature. The signals were detected by enhanced chemiluminescence reagent. Anti-tubulin was used to ensure the loading quality of the sample was consistent.

\section{Animal model}

BALB/c-nu mice (4-5 weeks of age, 18-20 g) were purchased from Shanghai Slick Laboratory Animal Co., Ltd. QBC939 cells transfected with sh-RPL34 and control cells $\left(5 \times 10^{6}\right)$ were suspended in $200 \mu \mathrm{l}$ of PBS and then injected subcutaneously into the right flank of mice $(\mathrm{n}=5$ /group). Mice were sacrificed 3 weeks after implantation, the tumors were dissected, and the tumor volume was calculated as follows: volume $=(\text { width })^{2} \times$ length $/ 2$. All experimental procedures were approved by the Institutional Animal Care and Use Committee of The Second Military Medical University.

\section{Statistical analysis}

SPSS version 22.0 (SPSS Inc., Chicago, IL, USA.) The $x^{2}$ test was used to analyze the associations among categorical data, including age, sex, tumor size, regional lymph node metastasis, positive margin, differentiation, $\mathrm{T}$ stage, and TNM stage. The Kaplan-Meier method was used to analyze the correlations between these clinicopathological parameters and tumor recurrence or overall survival. The significant predictive or prognostic factors in univariate analysis were enrolled in the Cox proportional hazards model to perform multivariate analysis. The P value for significance was established at 0.05 .

\section{Abbreviations}

RPL34: Ribosomal protein 34; HCCA: Hilar cholangiocarcinoma; RPS: Ribosomal proteins in small subunits; RPL: Ribosomal proteins in large subunits; DMEM:

Dulbecco's modified Eagle medium.

\section{Acknowledgements}

The authors would like to thank Dr Ying Chen from Changhai Hospital for analyzing the $\mathrm{HC}$ staining results.

\section{Authors' contributions}

$J X Q, F X$, and $L X W$ conceived the study, designed the research and drafted the paper; $L X, X Q G, W L Y, Y$ Cand $Y J$ Zperformed the experiments. All authors read and approved the final manuscript.

\section{Funding}

This work was partially supported by National Science Foundation of China (Number 81572856), and High Level Talen Introduction of Longhua Hospital Affiliated to Shanghai University of Traditional Chinese Medicine (LH02.51.002); Natural Science Foundation of Shanghai (Grant No. 16ZR1449200);

Shanghai Shen Kang Hospital Development Center Planning (Grant No. SHDC12017X14).

\section{Availability of data and materials}

The datasets used and/or analyzed during the current study available from the corresponding author on reasonable request.

\section{Ethical approval and consent to participate}

All animal experiments and procedures were approved by the Animal Ethics Committee of the Second Military Medical University, Shanghai, China, and all experiments were performed in accordance with the approved guidelines and regulations.

\section{Consent for publication}

All authors reviewed and approved the final manuscript. All authors supported publication of this manuscript.

\section{Competing interests}

The authors declare that they have no competing interests.

\section{Author details \\ ${ }^{1}$ Tumor Immunology and Gene Therapy Center, Third Affiliated Hospital of Second Military Medical University, Shanghai 200438, China. ${ }^{2}$ Department of Oncology, Longhua Hospital Affiliated to Shanghai University of Tranditional Chinese Medicine, Shanghai 200070, China. ${ }^{3}$ Institute of Biomedical Engineer- ing and Technology, Shanghai Engineering Research Center of Molecular Therapeutics and New Drug Development, School of Chemistry and Molecu- lar Engineering, East China Normal University, Shanghai 200062, China. \\ ${ }^{4}$ Departments of Surgery, Third Affiliated Hospital of Second Military Medical University, Shanghai 200438, China. ${ }^{5}$ Department of Medical imaging, Sixth Medical Center of PLA Chinese Hospital, Beijing 100010, China. ${ }^{6}$ Department of Pathology, Changhai Hospital, Shanghai 200433, China. ${ }^{7}$ Department of Bil- iary Tract Surgery Department III, Third Affiliated Hospital of Second Military} Medical University, Shanghai 200438, China.

Received: 8 May 2020 Accepted: 25 August 2020

Published online: 03 September 2020 


\section{References}

1. Skipworth JR, Keane MG, Pereira SP. Update on the management of cholangiocarcinoma. Dig Dis. 2014;32:570-8. https://doi.org/10.1159/00036 0507.

2. Ercolani G, et al. Changes in the surgical approach to hilar cholangiocarcinoma during an 18-year period in a Western single center. J Hepatobiliary Pancreat Sci. 2010;17:329-37. https://doi.org/10.1007/s00534-009-0249-5.

3. Soares KC, Kamel I, Cosgrove DP, Herman JM, Pawlik TM. Hilar cholangiocarcinoma: diagnosis, treatment options, and management. Hepatobiliary Surg Nutr. 2014;3:18-34. https://doi.org/10.3978/j. issn.2304-3881.2014.02.05.

4. de la Cruz J, Karbstein K, Woolford JL Jr. Functions of ribosomal proteins in assembly of eukaryotic ribosomes in vivo. Annu Rev Biochem. 2015;84:93-129. https://doi.org/10.1146/annurev-biochem-06061 4-033917.

5. Zhou X, Liao WJ, Liao JM, Liao P, Lu H. Ribosomal proteins: functions beyond the ribosome. J Mol Cell Biol. 2015;7:92-104. https://doi. org/10.1093/jmcb/mjv014.

6. Xie X, Guo P, Yu H, Wang Y, Chen G. Ribosomal proteins: insight into molecular roles and functions in hepatocellular carcinoma. Oncogene. 2018;37:277-85. https://doi.org/10.1038/onc.2017.343.

7. Bhavsar RB, Makley LN, Tsonis PA. The other lives of ribosomal proteins. Hum Genomics. 2010;4:327-44. https://doi. org/10.1186/1479-7364-4-5-327.

8. Sulima SO, Hofman IJF, De Keersmaecker K, Dinman JD. How ribosomes translate cancer. Cancer Discov. 2017;7:1069-87. https://doi. org/10.1158/2159-8290.CD-17-0550.

9. Pelletier J, Thomas G, Volarevic S. Ribosome biogenesis in cancer: new players and therapeutic avenues. Nat Rev Cancer. 2018;18:51-63. https:// doi.org/10.1038/nrc.2017.104.

10. Du J, et al. Regulation of multidrug resistance by ribosomal protein 16 in gastric cancer cells. Cancer Biol Ther. 2005;4:242-7. https://doi. org/10.4161/cbt.4.2.1477.

11. Kobayashi T, et al. Activation of the ribosomal protein L13 gene in human gastrointestinal cancer. Int J Mol Med. 2006;18:161-70.

12. Guo X, et al. Human ribosomal protein $\mathrm{S} 13$ promotes gastric cancer growth through down-regulating p27 (Kip1). J Cell Mol Med. 2011;15:296-306. https://doi.org/10.1111/j.1582-4934.2009.00969.x.

13. Hsu YA, et al. A novel interaction between interferon-inducible protein p56 and ribosomal protein L15 in gastric cancer cells. DNA Cell Biol. 2011;30:671-9. https://doi.org/10.1089/dna.2010.1149.

14. Huang CJ, et al. Faecal ribosomal protein L19 is a genetic prognostic factor for survival in colorectal cancer. J Cell Mol Med. 2008;12:1936-43. https://doi.org/10.1111/j.1582-4934.2008.00253.x.

15. Bee A, et al. siRNA knockdown of ribosomal protein gene RPL19 abrogates the aggressive phenotype of human prostate cancer. PLoS ONE. 2011;6:e22672. https://doi.org/10.1371/journal.pone.0022672.

16. Kim Y, Kim HD, Youn B, Park YG, Kim J. Ribosomal protein S3 is secreted as a homodimer in cancer cells. Biochem Biophys Res Commun. 2013;441:805-8. https://doi.org/10.1016/j.bbrc.2013.10.132.

17. Klinge S, Voigts-Hoffmann F, Leibundgut M, Arpagaus S, Ban N. Crystal structure of the eukaryotic $60 \mathrm{~S}$ ribosomal subunit in complex with initiation factor 6. Science. 2011;334:941-8. https://doi.org/10.1126/scien ce.1211204.

18. Liu H, et al. RNAi-mediated RPL34 knockdown suppresses the growth of human gastric cancer cells. Oncol Rep. 2015;34:2267-72. https://doi. org/10.3892/or.2015.4219.

19. Wei F, et al. Ribosomal protein $L 34$ promotes the proliferation, invasion and metastasis of pancreatic cancer cells. Oncotarget. 2016;7:85259-72. https://doi.org/10.18632/oncotarget.13269.

20. Yang S, et al. Over-expressed RPL34 promotes malignant proliferation of non-small cell lung cancer cells. Gene. 2016;576:421-8. https://doi. org/10.1016/j.gene.2015.10.053.

21. Dai J, Wei W. Influence of the RPL34 gene on the growth and metastasis of oral squamous cell carcinoma cells. Arch Oral Biol. 2017;83:40-6. https ://doi.org/10.1016/j.archoralbio.2017.06.035.

22. Fan $\mathrm{H}$, et al. Silencing of Ribosomal Protein L34 (RPL34) Inhibits the Proliferation and Invasion of Esophageal Cancer Cells. Oncol Res. 2017;25:1061-8. https://doi.org/10.3727/096504016X14830466773541.

23. Ji P, et al. Knockdown of RPL34 inhibits the proliferation and migration of glioma cells through the inactivation of JAK/STAT3 signaling pathway. J Cell Biochem. 2019:120:3259-67. https://doi.org/10.1002/jcb.27592.

24. Devitt ML, Stafstrom JP. Cell cycle regulation during growth-dormancy cycles in pea axillary buds. Plant Mol Biol. 1995;29:255-65. https://doi. org/10.1007/BF00043650.

25. Moorthamer M, Chaudhuri B. Identification of ribosomal protein L34 as a novel Cdk5 inhibitor. Biochem Biophys Res Commun. 1999;255:631-8. https://doi.org/10.1006/bbrc.1999.0145.

26. Luo S, et al. Highly expressed ribosomal protein L34 indicates poor prognosis in osteosarcoma and its knockdown suppresses osteosarcoma proliferation probably through translational control. Sci Rep. 2016;6:37690. https://doi.org/10.1038/srep37690.

27. Chen $Y$, et al. The prognostic potential and oncogenic effects of PRR11 expression in hilar cholangiocarcinoma. Oncotarget. 2015;6:20419-33.

28. $\mathrm{Yu} \mathrm{G}$, et al. PKM2 regulates neural invasion of and predicts poor prognosis for human hilar cholangiocarcinoma. Mol Cancer. 2015;14:193. https:// doi.org/10.1186/s12943-015-0462-6.

29. Jiao $X$, et al. ADAM-17 is a poor prognostic indicator for patients with hilar cholangiocarcinoma and is regulated by FoxM1. BMC Cancer. 2018;18:570. https://doi.org/10.1186/s12885-018-4294-9.

30. Kuang D, Wang GP. Hilar cholangiocarcinoma: pathology and tumor biology. Front Med China. 2010;4:371-7. https://doi.org/10.1007/s1168 4-010-0130-6.

31. Xu D, Miao Y, Gu X, Wang J, Yu G. Pyrophosphatase 1 expression is associated with future recurrence and overall survival in Chinese patients with intrahepatic cholangiocarcinoma. Oncol Lett. 2018;15:8095-101. https:// doi.org/10.3892/ol.2018.8278.

\section{Publisher's Note}

Springer Nature remains neutral with regard to jurisdictional claims in published maps and institutional affiliations.
Ready to submit your research? Choose BMC and benefit from:

- fast, convenient online submission

- thorough peer review by experienced researchers in your field

- rapid publication on acceptance

- support for research data, including large and complex data types

- gold Open Access which fosters wider collaboration and increased citations

- maximum visibility for your research: over 100M website views per year

At $B M C$, research is always in progress.

Learn more biomedcentral.com/submissions 